\title{
Introduction to the first issue
}

\author{
Ioan Dziţac
}

In this inaugural issue we present:

- an editorial article, with a general presentation of IJCCC and this introduction with short description of the papers published in this first issue;

- one anniversary article dedicated to centenary of Kurt Gödel (1906-1978) and two anniversary articles dedicated to centenary of Grigore C. Moisil (1906-1973);

- some selected papers from the International Conference on Computers, Communications \& Control, June 1-3, 2006, Băile Felix - Oradea, Romania, ICCCC 2006;

- two regular papers.

\section{Introducing the papers}

Daniel C. Doolan and Sabin Tabirca's paper ${ }^{1}$ discusses how a Java 2 Micro Edition (J2ME) application may be developed to visualize a wide variety of differing fractal types on a mobile phone. An integrated tool has been developed by authors to generate a variety of two dimensional fractals (Mandelbrot Set, Julia Set, Prime Number Fractal and the Plasma Fractal).

Banshider Majhi, Y Santhosh Reddy, D Prasanna Babu's propose in their paper a new feature extraction scheme for offline signature verification. The method uses geometric center for feature extraction and Euclidean distance model for classification. This classifier is well suitable for features extracted and fast in computation. The method proposed in this paper leads to better results than existing offline signature verification methods.

Gheorghe Păun initiated membrane computing, most known as P systems (with "P" from "Păun"; for more details see http://psystems.disco.unimib.it) by paper "Computing with membranes", published in Journal of Computer and System Sciences, 61, 1 (2000), 108-143 (first circulated as TUCS Research Report No 208, November 1998, http://www.tucs.fi). In the paper published in this issue he continues the attempt to bridge brane calculi with membrane computing, following the investigation started in the paper L. Cardelli, Gh. Păun, An universality result for a (mem)brane calculus based on mate/drip operations, Intern. J. Foundations of Computer Sci., 17, 1 (2006), 49-68.

Dana Petcu, Cosmin Bonchiş, Cornel Izbaşa present in their paper ${ }^{2}$, a case study of a Web service-based Grid application for symbolic computations (known as Computer Algebra Systems (CAS)), using Maple2g (Maple-toGrid).

Imre Rudas and Janos Fodor summarizes in their paper ${ }^{3}$ the research results of the authors that have been carried out in recent years on generalization of conventional operators. Aggregating uncertain information is an important issue in the study of Intelligent Systems. In their contribution, the authors present an overview on generalized operators from the point of view of Information Aggregation. In this spirit, a comparative study of triangular norms and conorms, uninorms and nullnorms, generalized conjunctions and disjunctions and distancebased operations is presented.

Milan Stanojevic and Mirco Vujosevic's propose in their paper ${ }^{4}$ a new original more efficient algorithm formulation and implementation for solving relatively low dimensions Steiner Tree problem on graph.

Athanasios D. Styliadis, Ioannis D. Karamitsos, Dimitrios I. Zachariou's paper ${ }^{5}$ introduces the GIS elearning implementation, based on a set of teaching (lecturing) rules according to the cognitive style of learning preferences of both the learners and the lecturers as well.

\footnotetext{
${ }^{1}$ Selected from ICCCC 2006

${ }^{2}$ selected from ICCCC 2006

${ }^{3}$ Plenary invited paper of ICCCC 2006

${ }^{4}$ Invited paper of ICCCC 2006

${ }^{5}$ Invited paper of ICCCC 2006
} 


\section{Introducing the anniversary articles}

Gabriel Ciobanu's article presents some impressions about life, work, and foundational views of Kurt Gödel, after his participation to the international symposium celebrating the 100th birthday of Kurt Gödel, organized between 27-29 April 2006 by the Kurt Gödel Society and University of Vienna. Gabriel Ciobanu has been accepted to this symposium with a contribution regarding a new characterization of computable real numbers.

Solomon Marcus present in this first issue of IJCCC a very well documented article ${ }^{6}$, devoted to 100 years since the birth of Great Romanian Mathematician and Computer Pioneer (IEEE-1996), Grigore C. Moisil (19061973).

In 1976, 1980 and 1992, acad. Solomon Marcus has edited and prefaced the following volumes:

- Gr. C. Moisil, Opera matematica, vol.I, Editura Academiei, Bucuresti, 1976 (preface, edition and introductory study).

- Gr. C. Moisil, Opera matematica, vol.II, Editura Academiei, Bucuresti, 1980 (preface, edition and introductory study).

- Gr. C. Moisil, Opera matematica, vol.III, Editura Academiei, Bucuresti, 1992 (edition and introductory study).

George Georgescu, Afrodita Iorgulescu, Sergiu Rudeanu, three remarkable Moisil's disciples, presents, in their technical paper ${ }^{7}$, a very concise and updated survey emphasizing the research done by Grigore C. Moisil and his school in algebraic logic ( $n$-valued Lukasiewicz-Moisil algebra, $\theta$-valued Lukasiewicz-Moisil algebra, Post algebra etc.).

Ioan Dziţac

Executive Editor of IJCCC

Agora University

8, P-ta Tineretului, 410526

Oradea, Romania

E-mail: idzitac@univagora.ro

${ }^{6}$ Plenary invited talk of ICCCC 2006

${ }^{7}$ Invited paper of ICCCC 2006 